\title{
ICT for Innovation in Advanced Banking
}

\author{
Milvina Terzieva ${ }^{1}$, Dimitar Karastoyanov ${ }^{1}$ \\ ${ }^{1}$ Institute of Information and Communication Technologies, Sofia, Bulgaria \\ Emails: msalabasheva@yahoo.com, dimikara@abv.bg
}

\begin{abstract}
The article presents the process of entering ICT and digital innovations in modern banking. Statistics on the use of public clouds by various companies are cited. Types of regulations in European Union on the entry of cloud services in the banking sector are considered. The requirements of the EU Payment Service Directives are analysed. New banking functions and open banking are described. Existing models of open banking and the interaction between large digital companies and large money providers are discussed.
\end{abstract}

Keywords: Cloud, fintech, ICT, open banking.

\section{Introduction}

Mobile payments and digital wallets are now part of the daily routine of all active users. The Fintech (Financial Services Platforms) sector is respected and this puts the financial industry to the test of innovating at the fastest possible pace. Years ago, the bank moved to the computer, and now it has to be in the consumer's pocket. There is an evolution in payments. They need to be instantaneous.

As we enter a decade of innovation and change, financial institutions face a number of challenges in the form of shifting customer expectations, emerging technologies and alternative business models [1]. However, as the industry tries to meet these challenges, perhaps the best solution is to look for a technology that more than a decade ago created destructive waves in the technology industry: cloud computing.

While data-sharing solutions were available in the early 1970s, telecommunications companies created virtual private network (VPN) services in the 1990s that switched traffic between servers, something that was evolving to cover the entire network infrastructure. That's when technology companies see the potential of 
the cloud on a large scale. In August 2006, Amazon created Amazon Web Services, introducing its cloud to resilient modern banking. Google followed suit in April 2008, releasing a beta version of its App Engine. Microsoft introduced Microsoft Azure in 2010, announcing its development two years earlier.

\section{Cloud Technologies in Modern banking}

In 2020, cloud computing became part of the core IT. The global market for public cloud services is expected to reach $\$ 266$ billion in 2020 [2]. 94\% of enterprises use public cloud in some form or another [3], while $66 \%$ have a central team dedicated to the development of cloud technologies [4]. While financial institutions are initially either slowing down the adoption of cloud computing and new technologies, market challenges and start-ups are not. At the end of 2018, 14\% of revenues from retail banking and commercial banks were redirected to new entrants, many of which are based on cloud technologies and agile technologies [5].

As 2020 progresses, regulations remain a major controlling factor for financial institutions, continuing to control, regulate and condemn. However, while this factor puts pressure on large banks, their customers require faster and more responsive experiences when interacting with their products, guided by an example set by technology giants. As a result, there is a greater focus on the front office and moving away from traditional banking operations. Banks are beginning to see the profitability that comes from providing customers with an innovative experience [6]. To cope with growing IT requirements and better innovate their customer services, many large banks have launched large-scale digital transformation projects worth hundreds of millions. The pace at which financial institutions are embracing cloud platforms is accelerating and is a symbol of the strong intentions of sectors to rely on this technology in the near future. The adoption of the cloud is no longer just a technological solution to reduce costs, but it is imperative for businesses to reduce time to market, increase flexibility and improve the overall customer experience of an enterprise.

In order to meet the enhanced security requirements (authentication) when providing access through something that the customer knows and something that the customer has physically (mobile phone, signature written on a chip card, token) [7], [8], the European Union has introduced the "Payment Service Directive" (PSD). Part of this regulation is the requirement to apply strong customer authentication when performing payment transactions, which aims at all participants in the payment market to provide a high degree of protection of customers' funds against malicious attempts by fraudsters to gain access to them. As the payment space continues to evolve with rapidly increasing mobile and internet payments, the EC has revised the initial PSD and acknowledged that it needs improvements and clarifications to keep pace and ensure customer security. As a result, PSD2 entered into force on 13 January 2018. Like PSD, PSD2 is a significant step forward in the regulations for the payment industry. In addition to renewed support for PSD's existing objectives, promoting 
increased competition and cost-effective choice for consumers by opening up the payment market to new entrants, PSD2 aims to:

- better protection of financial data of users with stricter security requirements, such as stricter authentication;

- requiring banks to provide open communication interfaces (Application Program Interface - APIs) that allow access to third-party providers (TPPs);

- more transparent conditions and information requirements for payment services;

- redefining the rights and obligations of consumers and payment service providers;

- clarification of the criteria and scope of exceptions.

Fintech has been slowly destroying banking relationships for years. Beyond companies that are traditional banks, non-bank brands such as PayPal, Venmo, Mint and Rocket Mortgage offer customers easy ways to make payments, understand their finances and get approved for a home loan. As companies known for mobile card processing and e-commerce seek approval for banks or partnerships, additional business outside the traditional banking sector makes similar offers - opening the door to a new business sector facing banks (Fig. 1).

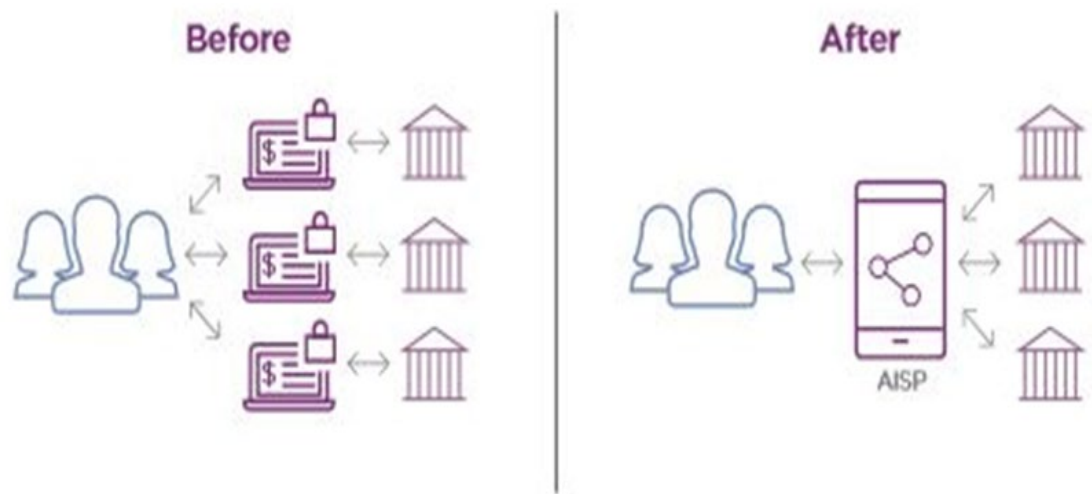

Fig. 1. Open banking

\section{New Bank Functions and Open Banking}

Apart from the general bank offers (on deposit account, debit card and payments), in 2020 the sector will start focusing on personalized functions by specific target groups:

- freelancers - need additional support in calculating taxes, deductions and employee benefits;

- immigrants - support the quick opening of online accounts as a newcomer and have access to savings and credit;

- small enterprises - support needed to manage receivables and monitor costs; 
- minors/children - an education-based bank to learn how to effectively budget, save and build credit;

- adults/"at risk" adults - personalized support for access through power of attorney, guardianship, family, preservation of wealth, retirement benefits and health information;

- passengers - the ability to use a global account and card without additional fees or challenges.

The outlook is bright and expansive for established neobanks and emerging, offering a personalized experience for "niche" consumer segments. 2020 is expected to be a period of transformation for the financial services sector. Traditionally slow to innovate, the industry has been turned upside down with new Fintech, using data and extracting examples from other sectors to undermine established players. Switching to open banking allows the provider to be authorized as an "Account Information Service Provider" (AISP), which means that it can now use the APIs securely. This means that they can now act as a single, unified interface to all the financial information of a person or business. Reproducing the growing convenience requirements, this enables the connection of external bank accounts to the provider, giving consumers and businesses a 360-degree view of their balance sheets, transactions and everything related to banking within one application.

The consequences cannot be overestimated. Open banking will encourage consumers to be more aggressive with credit cards and savings accounts. This could herald the end of bank loyalty. Revolut was the first to announce it and made it a pioneer even among the contender banks. Everyone's eyes are watching to see if the open application system is working effectively. And it's easy to see why - in theory, this will open the door to additional AISP functions for sectors other than banking. In retail we can see that it applies to functions that have relationships between borrowers and credit providers. For example, we can see the emergence of a single application for a company for credit, delivery or purchase of inventory, which looks at the whole market. Digital brands like Revolut are in the best position to take advantage of these new features. Unlike retailers, these companies have fewer barriers to innovation, which allows them to be much more flexible in implementing new initiatives. Companies like Asos, Boohoo and of course Amazon are expected to start testing the limits of what is possible.

However, the risks posed by open banking should not be overlooked. With open third-party APIs, open banking makes organizations vulnerable to potential cyber-attacks, as they can no longer hide critical applications behind firewalls. The banking industry usually has good protection, but a huge part of the responsibility falls entirely on the shoulders of suppliers like Revolut. Ultimately, any stumbling block or omission can lead to serious financial and reputational failures, and stop open banking in its infancy. This means that the security of the API is more critical than ever for the company to mitigate any threat. 
Open banking is at the heart of innovation and can transform not only the banking sector but also any industry. However, since 2019 was registered as the worst year for registering data breaches leading to information disclosure, security has become a key focus in the industry. Ultimately, the move to open banking is a sign that the traditional model of retail banking is disappearing. It offers convenience by giving users greater visibility over their finances and gets rid of the traditional "pain" of managing multiple accounts [9], [10].

\section{Existing Models of Open Banking}

Until recently, consumers' financial data was kept centrally within their financial institution. But it has begun to change with the implementation of various open banking initiatives that have evolved over the past decade and launched in recent years around the world [11]. It has become clear that the future of banking will be driven by open business models and APIs. Recently, the biggest beneficiaries of switching accounts are banks such as HSBC, Santander and Nationwide, along with FinTechs such as Monzo, Starling and Revolut. In the US, although regulatory changes are likely to be far away, a more open model is inevitable, as major technology players such as Google, Apple, Amazon and Facebook are making payments and other activities difficult, as is the case with Apple's new Apple Card initiative, in partnership with Goldman Sachs. Although it may not be as cutting-edge as some would like, Apple is stamping its payment space by declaring, "Created by Apple, not a bank", in its launch campaign. Much to the horror of a banker, this is likely to resonate with consumers more than they would like.

Meanwhile, the advent of super application models in the East by technical giants such as Alibaba and Tencent has introduced consumers to a new way of consumer banking, especially in the area of payments. Challenger banks such as MYbank and WeBank (supported by Alibaba and Tencent, respectively) have grown significantly over the past few years. At the same time, the subsidiary of Alibaba Ant Financial is growing rapidly outside its home market, China, following a strategy to serve the huge market of Chinese tourists and accustomed to the AliPay platform. The super app is connected to over 200 institutions, including over 100 banks, 60 insurers and 40 wealth management companies and security brokerage services.

Thousands of FinTech start-ups have taken market share in key revenue areas, and the banks that partner and invest in them have not slowed the pace and impact of the FinTech ecosystem. The move towards open banking and the large-scale efforts of the dominant technology platforms will only exacerbate the problems facing banks [12], [13]. Technology will continue to offer new added value that was never expected. This will work to restore customer closeness and trust by acting as a personal chief financial officer (CFO) for the client at every stage of life. The winners will be those who can create longer-term relationships, optimize costs and build more proactive and personalized data that extends beyond traditional financial services. Re-grouping gives us the opportunity to re-imagine - not to build on the past, but to 
plant future business models. In a world where Chinese citizens with Chinese bank accounts can spend their entire lives in the super apps Alipay and WeChat, while outsiders pay in cash; where $47 \%$ of American consumers still write checks; where people in Africa can pay and receive microloans on their mobile phones for a moment - the answer to the ancient question to the Promised Land: "Have we arrived yet?" is unfortunately "No, not yet". As Chris Skinner writes in his book Digital Human: "The new world is one of the transitional relationships, short-term commitments and everything online all the time. However, the financial system is built for lifelong relationships, long-term commitments and everything else". If the industry is to thrive in a new environment with competition from global technology companies, we must use the scale and confidence of existing banks, the agility and focus of FinTech startups. It is time to adopt open banking business models or banks will cease to exist.

In particular, three models for open banking stand out (Fig. 2):

- Internal - Traditional banks develop their own APIs to develop products internally or to integrate them with products with third-party white-labels. The Bank retains ownership of the distribution and user interface;

- Platform banking - Third parties create new products and offers for bank customers based on the basic infrastructure of the bank;

- Distributor - Third parties share customer access with banks, leading to broader and more efficient customer offerings.
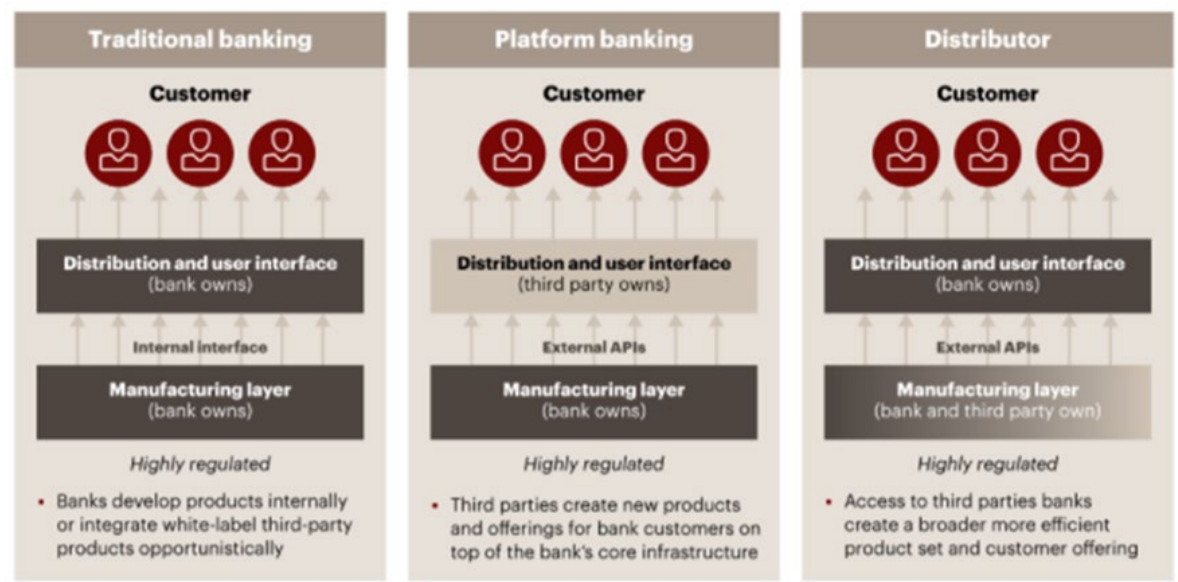

Fig. 2. Open banking models

One possible scenario of open banking is "The Rise of the Giants" - the largest digital companies are merging with major money providers and banks, and entering retail banking. These technology titans are expanding into retail banking, taking advantage of their scale in terms of both customer reach and proximity to customers, often their "last step" to consumers. According to the UN, by 2025, about 300 million people will live outside their homeland. No Financial Institution (FI) can avoid the need to expand the scope of cross-border services as the pace of global migration 
increases. By offering more complete cash flow solutions for both individuals and business customers, FI can only benefit from the two key trends. The continuous growth of global migration and cross-border business means that international money movement is now mandatory, leading to more and more customers in need of international remittances and payment services. Globalization means that a truly global money movement service has really emerged.

To offer added value to end customers and competitive service prices, you can resort to integrating an Account Base Money Transfer (ABMT) solution into the core system of a digital or banking giant. This type of ABMT is a solution for offering real-time money transfer services and can be integrated into their existing sales system (POS), including the digital equivalent of the channel. This solution is aimed at financial institutions (FIs) that want to expand their business by expanding their remittance and payout capabilities using their partnership with a fast remittance provider. ABMT allows customers to send money to countries and territories through the provider's extensive network by paying out cash and accounts (APN) and paying from an account (bank or wallet). This will increase the trust in the brand and its competitiveness. ABMT is the ability to send money directly from the sender's bank account to be paid in cash within minutes at any location in the partner network around the world or directed by the recipient to be credited to mWallet or his bank account. This allows bank users to send money transfers through various banking channels such as online banking, bank branch locations, telephone banking, mobile banking, ATM.

ABMT supports the following channels for financial institutions (FIs):

- Online (web) - the service is offered through the online portal of FI.

- Mobile (app) - the service is offered through the FI mobile portal (used on a mobile phone).

- ATMs - the service is physically offered at FI's ATMs.

- Self Service Kiosks - the service is available at FI's self-service kiosks.

- Retail - a client visits a physical location to personally perform a transaction assisted by an employee (eg FI bank cashier). The banking system is integrated with the partner API to offer its service.

Global Network of Money Transfer Provider offers a highly efficient addition or replacement of an existing correspondent banking network. The movement of money through this network can be faster and more efficient than correspondent banking networks. Offers a wide range of system integration solutions, including APIs and hosted options.

\section{Conclusion}

Telecommunications companies offer financial services, and many banking institutions offer telecommunications services. Telecommunications operators offer traditional banking products such as issuing and maintaining credit and debit cards. 
Banks are already outsourcing part of the capacity of the communication line to other consumers and are actively using telecommunication systems

Open banking is growing in Europe. The concept of open banking has been central to the financial services dialogue for many months, fueled in part by the revised EU Payment Services Directive. Open banking is a model based on the exchange of bank data between two or more non-aligned countries in order to provide improved market opportunities. The development of ICT and their expansion in all areas of human activity will lead to the emergence of many new banking functions and financial services.

\section{References}

1. Office of Tech. Assessment, U.S. Congress, U.S. Banks and International Telecommunications 19 (Background Paper No. Ota-Bp-Tct-100, 1992) [Hereinafter Office of Tech. Assessment].

2. Gartner report "Forecast: Public Cloud Services, Worldwide, 2018-2024, 2Q20 Update", https://www.gartner.com/en/documents/3987438/forecast-public-cloud-servicesworldwide-2018-2024-2q20-

3. Flexera report "Rightscale 2019 State of the Cloud", https://resources.flexera.com/web/media/documents/rightscale-2019-state-of-the-cloudreport-from-flexera.pdf

4. Cloud computing trends: 2020 State of the Cloud Report, https://www.flexera.com/blog/industry-trends/trend-of-cloud-computing-2020/

5. Accenture Technology Advisory Cloud Readiness Report - Banking

6. Malaquias, R. F., Hwang, Y.: Mobile banking use: A comparative study with Brazilian and U.S. participants. International Journal of Information Management 44, 132-140 (2019), https://doi.org/10.1016/j.ijinfomgt.2018.10.004

7. Blagoev, I.: Neglected cybersecurity risks in the public Internet hosting service providers. Information \& Security: An International Journal 47(1), 62-76 (2020), https://doi.org/10.11610/isij.4704

8. Del Gaudio, B. L., Porzio, C., Sampagnaro, G., Verdoliva, V.: How do mobile, internet and ICT diffusion affect the banking industry? An empirical analysis. European Management Journal, 2020, https://doi.org/10.1016/j.emj.2020.07.003

9. Fatkieva, R., Evnevich, E., Yoshinov. R.: State-of-the art and trends in network security control. Problems of Engineering Cybernetics and Robotics 72, 41-55 (2020).

10. Tomov, P., Zankinski, I., Balabanov, T.: Training of artificial neural networks for financial time series forecasting in android service and widgets. Problems of Engineering Cybernetics and Robotics 71, 50-56 (2019).

11. Lwoga, E. T., Sangeda, R. Z.: ICTs and development in developing countries: A systematic review of reviews. The Electronic Journal of Information Systems in Developing Countries, (2018), https://doi.org/10.1002/isd2.12060

12. Chmielarz, W., Zborowski, M.: Analysis of e-banking websites' quality with the application of the TOPSIS method - A practical study. Procedia Computer Science 126, 1964-1976 (2018), https://doi.org/10.1016/j.procs.2018.07.256

13. Vives, X.: Competition and stability in modern banking: A post-crisis perspective. International Journal of Industrial Organization 64, 55-69 (2019). 